SOCIAL RESEARCH REPORTS

ISSN: 2066-6861 (print), ISSN: 2067-5941 (electronic)

\title{
TEENS' PERCEPTION AND BEHAVIOR REGARDING ALCOHOL CONSUMPTION. PREVENTION STRATEGIES
}

\author{
Viorica-Cristina CORMOS
}

Social Research Reports, 2019, Vol. 11, Issue 3, pp. 35-43

The online version of this article can be found at:

www. researchreports.ro

\section{https://doi.org/10.33788/srr11.3.3}

Published by:

Expert Projects Publishing House

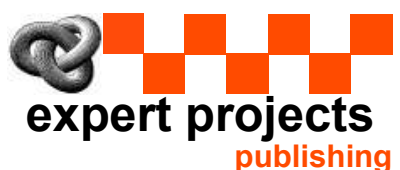

Covered by Index Copernicus International www.indexcopernicus.com

Directory of Open Access Journals

www.doaj.org

On behalf of:

Center for Program and Social Development

Aditional services and information about Social Research Reports can be found at:

www.researchreports.ro 


\title{
TEENS' PERCEPTION AND BEHAVIOR REGARDING ALCOHOL CONSUMPTION. PREVENTION STRATEGIES
}

\author{
Viorica-Cristina CORMOS ${ }^{I}$
}

\begin{abstract}
Adolescence is a stage of life that begins, according to specialists, around the age 13-14 and can extend even until 20 years old. The end of adolescence marks the beginning of maturity and the transition to adulthood. This period is characterised by a series of obstacles, whereby psychological and behavioural imbalances are often identified. For teenagers, showing off, being different and impressing their friend groups are common. As a result, alcohol use is one of the many options adolescents may choose to reach such "performance." Many of them are nonchalant regarding alcohol use and consider drinking a temporary phase with no consequences. Others have deeper knowledge about drinking, but don't apply them. In this paper, I will highlight some aspects on perception and behaviour in adolescents regarding alcohol use, which were analysed based on an interview applied to teenagers in several high schools in Suceava County. I will also detail the strategies and possibilities of prevention to reduce this phenomenon among adolescents.
\end{abstract}

Keywords: adolescents, alcohol, perception, behaviour, strategy, prevention.

\section{Introduction}

Adolescence is a life stage that begins, according to specialists at age 13-14 and may extend in some cases, according to some studies, to 20-21 years. The end of adolescence marks the beginning of adulthood, both from biological and physical points of view. At the same time, beyond the beauty and innocence of this life stage, it is also characterized by some obstacles predominantly emerging from mental and behavioral imbalances that may lead to deviant behavior, delinquency and substance use.

Teenagers can start drinking alcohol for several reasons: out of curiosity, when they find their life boring and look for something to make them feel that they live more intensely, the desire to join a certain group of friends, when this habit is present in the family and the adolescent takes over the parental model, when

1 "Ștefan cel Mare” University of Suceava, ROMANIA. E-mail: cristinacormos@yahoo. com 
unpleasant events occur in their life and they find a short-term solution in alcohol, following a deception in teenage love, show-off, etc.

Adolescence is not an easy life stage, as teenagers are prone to many risks. Therefore, it is important for them to receive support and supervision from school, family and competent institutions, and specialists involved in prevention activities, respectively. It is important that the prevention actions pursue "educating, informing, raising awareness among adolescents of not starting or delaying the onset of drug use and avoiding turning experimental or occasional use into customary drug use respectively; minimizing risks in the families of adolescents; reducing the influence of risk factors in adolescents' life environment" (National Strategy for Youth 2014-2020).

\section{Alcohol use among teenagers}

Adolescence is the period of life that plays a promoting role, and at the same time lays the foundation for a harmonious psycho-social and biological development for the future adult. Maurice Debesse stated that "there is no other period of growth in which development is more sensitive than during adolescence" (Debesse, 1970: 87). The "sensitive" character of this period consists in the fact that the events that occur during it, the choices made respectively, inevitably influence the long-term development of the individual. In other words, what happens during adolescence has repercussions in the development of the future adult. Adolescence may be regarded as a life stage characterized by numerous, different types of transformations (biological, psycho-social, etc.). It is considered a "distinct stage in the development of the individual, placed between childhood and youth, with characteristic features on biological and psychosocial levels" (Zamfir \& Vlasceanu, 1998: 8) From a psychological point of view, this life stage is shaped as "a phase of affective and intellectual restructuring of the personality, a process of individualization and metabolization of the physiological transformations related to the integration of the sexual body" (Doron \& Parot, 2004: 24).

Many studies and social environments discuss late or prolonged adolescence. This interval represents the beginning of a new life stage, namely adult life. The behavioral and mental changes already outline quite clearly an individual prepared to face life challenges, all his actions being characterized by maturity. The desire to be independent becomes greater. Uncertainty and the willingness to let someone else decide for him are lost, and replaced by firm independence. At this moment, a clearly defined system of values and beliefs is present, which practically forms the identity of the adult. The feeling of safety and comfort that he used to experience when close friends/family decided for him is replaced by the desire to risk and experiment on his own. He becomes stable on his own choices, understanding that he is fully responsible for them. Thus, he develops an ability to make his own decisions, most often considering compromise as a solution for solving problems or achieving objectives.

Adolescence is characterized by transformations at the relational and decisionmaking level, as well as in what concerns intellectual and emotional maturity. The 
teenager may follow an upward trajectory if he is properly guided and educated. However, there are several factors that may influence his life and impel him to make certain decisions that can affect him both during adolescence and adulthood. Adolescence is the time of development, growth and change and, therefore, it is expected that a child undergoing the process of personality maturation will try new experiences or become rebel. Thus, adolescence is a period marked by some obstacles, which frequently lead to the formation of mental and behavioral imbalances. Showing off, being different and impressing their friend groups are often encountered in adolescents. As a result, alcohol consumption is one of the options many adolescents may choose to reach such "performances". Many of them are nonchalant regarding alcohol use and consider drinking a temporary phase with no consequences. Others are aware of what normal behavior in society is, and are able to find the limit between drinking for pleasure and excessive drinking. Generally, teenagers have certain knowledge about proper alcohol use, but choose to ignore it.

Drinking is widely accepted in our society as a way to celebrate certain achievements, as a near-replacement of medicine or as an activity performed in various social groups. Due to the fact that alcohol use is so readily accepted, teenagers may ignore the dangers that arise from drinking. They wish to look much older than they really are and can be thus pressured by their friends to behave accordingly and act as adults. These requirements may subject teenagers to substantial effort and may result in excessive drinking.

Adolescents' attitude towards alcohol often depends on how it is viewed by their families. Families where alcohol use plays an important, mood-changing role or those where alcohol is used as a form of treatment for certain conditions may pass these habits on to their children. Recent studies have shown that "most adolescents consume alcoholic beverages, 3/4 of young people drink the first alcoholic beverage at the age of 13 and $7 \%$ of young people aged between 15 - and 16-years drink two bottles of beer or 0.51 of wine weekly" (https://sites.google. $\mathrm{com} / \mathrm{site} /$ educatiepentruparinti2012/-adolescenta/adolescentii-si-alcoolul). Due to the fact that alcohol use is accepted so easily, teenagers can ignore the dangers that arise from its use. An adolescent can become an alcoholic in 8-16 months of heavy drinking, when, normally, an adult becomes an alcoholic in 5-15 years.

Alcohol use in adolescents is based on a number of risk factors: individual factors (somatic or mental disorders such as sleep or eating disorders or depression, behavioral disorders such as running away from home or theft); family-related factors (family separation, parents' drinking habits, parent-child tension or death of one parent); environmental factors (emigration, unemployment, poverty, exclusion, marginalization). In this context, we add the psychological factors that assume the "existence" of predisposition toward alcoholism, present in talkative people, dependent and childish people, those with low tolerance for frustration, those unable to fulfill their social responsibilities, with narcissistic predispositions, feelings of insecurity and inferiority" (Neamtu, \& Stan, 2005: 403).

Regarding the behavior of adolescents under alcohol use, they can participate much more easily in actions initiated by violent groups, they can show irresponsible sexual behavior, resulting in sexually-transmitted diseases, unwanted pregnancies, etc., or they can engage in various delinquent actions. Alcohol abuse is most 
often associated with smoking and drug use. "Alcoholism, as a phenomenon with influences on social life, assumes the involvement of alcohol in the creation of deviant behavior, and its role in triggering criminal behavior is indisputable. (...) Alcohol appears as a trigger factor in many types of offenses with judicial implications: theft, rape, robberies, crimes, etc.” (Neamtu, \& Stan, 2005: 400)

\section{Methodology}

Teenagers may start drinking alcohol for several reasons. First of all, they perceive their lives as "trivial" and "routine", and as a result some find a "lifeline" in drinking. The short-term effects of alcohol use give them a short-term feeling that their life is more interesting and they live it more intensely. In most cases, they return to drinking in order to take their "dose of happiness" and gain courage in undertaking certain actions. Another possible cause for a teenager to start drinking is that he or she wants to join a particular group in which alcohol use is common. If the teenager does not adopt this behavior, he/she will not be perceived as "cool" and thus will not be able to prove his affiliation to the group. Failure to follow the behavior imposed by such a group leads to offending, labeling, marginalizing and eventually eliminating the adolescent from the group. "The intense emotionality characteristic to adolescence and the norms promoted within the group of friends show an increased risk for substance abuse" (Simons, Whitbeck, Conger and Melby, 1991, apud. Dumulescu, \& Matei, 2017: 41).

Additionally, other aspects may influence adolescent drinking behavior, such as the parental model. If one or both parents are alcoholics, the young man will likely follow the model of the person in charge of his upbringing and education up to that age. "Parents are the role models in young people's lives for what it means to be an adult. Often this discrepancy between what the parent does and what he or she says leads to a distrust in the parent and a slight "rebellion" in the adolescent, which ultimately may contribute to the adoption of behaviors" (Dumulescu, \& Matei, 2017: 41) There are other factors influencing adolescent drinking: the divorce of the parents or the death of one of the parents, drawing attention of others, including the parents if they neglected them at a certain moment, the show-off, the deception following a false friendship, etc. "The risk of alcoholism is increased, however, when drinking is performed in emotional situations or where there is ambivalence towards alcohol" (Radulescu \& Damboveanu, 2006: 443).

Starting from these specifications, I considered it necessary to carry out a qualitative study in which I highlighted personal issues of adolescents who drank alcoholic beverages moderately or excessively. This study was based on the interview method, conducted on a sample of 20 students (15 boys and 5 girls) in the 12th grade, in four high schools in the Suceava County. The interviewed students were 18 years old, and their selection was performed after this study was introduced during their educational classes.

The working tool used was the interview guide, and the interview analysis is a mixed thematic analysis, depending on the previously established topic. Most of the students were open to the analyzed topic and offered the requested information, 
according to the questions asked. This study was based on the hypothesis that "Although adolescents are informed, most of them drink alcohol, in some cases even excessively".

\section{Interview}

1. What do you know about alcohol?

2. What do you know about excessive drinking?

3. What is your perception of alcohol use?

4. If you drink alcohol, when do you do this?

5 . How about your friends / colleagues?

6. If you drink alcohol, what is the amount and type of alcohol used?

7. How about your friends / colleagues?

8. If you drink too much, what makes you do this?

9. How do you feel in your group of friends if you drink too much alcohol? 10. What actions do you think should be undertaken to learn more about heavy drinking?

\section{Results}

\section{Thematic analysis}

T1. What is known about alcohol and its heavy use

Following the dialogue with the twenty students, it is observed that they know to some extent the problem of alcohol use. They specified that there were informed through various activities at school, but also through the online environment and the media. Moreover, some of them saw in their own family different types of alcohol use and its long-term effects. Despite this, some of them drink, especially at parties and in their groups of friends.

"Such topics were also discussed during the educational classes. NGO representatives were also invited, and gave us more information on alcohol use. But even so, most of them are not really taken seriously. Many of my friends drink. I usually drink a beer when I go out with them, otherwise I'm being laughed at. "(F.S., 18 years old, boy)

"I know it's not good to drink too much. I have an uncle who ended up losing his job and his family left him because he became an alcoholic. And he is very ill. "(D.J., 18 years old, boy)

T2. Perception of alcohol use.

Four of the interviewed adolescents (three girls and one boy) mentioned that they have a negative opinion about alcohol use and consider that its use is not necessary; twelve of them stated that alcohol can be used occasionally and where 
this is customary, but in moderation; four others considered drinking as a normal activity, which can be performed by anyone anytime and in any amounts, and stressed that drinking is not "as black as it is painted" and that "a party is not a party, and having a good time is not so fun without drinking".

"I believe anyone can drink at a party or with friends, within certain limits, and that depends on each one. And if you are over 18 years old, you can do this, nobody can stop you if you want to drink". (P.F., 18 years old, boy)

"What can I say, I don't see drinking as black as it is painted. I go out with friends, we drink a beer, two, three, until we start feeling good. You can't even go to parties or in clubs and say - you know, I don't drink ... You are definitely excluded in this case, and besides, a party is not a party, and having a good time is not so fun without drinking" (D.G., 18 years old, boy).

\section{T3. Rules for drinking, amount and type of alcohol used}

Of the twenty adolescents, sixteen indicated that they used to drink and still drink alcohol. Twelve of them drink only occasionally, and four indicated that they drink often and sometimes large amounts of alcohol, to feel good. They generally drink beer, wine, whiskey, vodka, cognac, cocktails, and less liquor, natural alcohol and other homemade alcoholic beverages (e.g. sour-cherry, blueberry or blackberry drinks etc.).

"Yes, I drink occasionally when I go to parties or family events. Otherwise not much. And I drink wine in particular." (R.S., 18 years, girl)

"How can I refuse drinking at parties? that would not be a party anymore... And my friends would laugh at me if I didn't drink with them. We mostly drink beer, or we start with whiskey or vodka and continue with beer. In clubs we always drink whiskey or vodka, but also beer (...) And it is true, we get drunk, I felt really bad on several occasions ... but it goes away". (T.S., 18 years, boy)

\section{T4. Alcohol use and the group of friends}

Based on the information gathered from the interviewed adolescents, who occasionally or periodically drink, alcohol appears to be generally associated with the group of friends and parties. None of these teenagers drank alone, such as alcohol drinking as a result of disappointment or sadness. Alcohol consumption among interviewed adolescents is associated with having fun and good time or the desire to show off, to impress their group of friends.

"If we have a few drinks we feel good and have courage. We are highly regarded among friends, we have fun, we joke, we do all kinds of crazy things. We have a lot of fun... "(P.O, 18 years old, boy)

"The worst thing is that when we drink too much, we get to contradict each other, to offend each other and even to fight. But the next day when we feel better, we are still 
friends. That's what getting drunk is about." (T.S., 18 years, boy)

\section{T5. Actions proposed by adolescents regarding excessive drinking}

The interviewed adolescents generally consider information as the most important of all actions. Those who admitted that they drink regularly, consider that such actions are not necessary, specifying that it is not "as serious as it seems." However, some of them consider that it is important to have actions that make heavy drinkers understand how serious it is to continue drinking and to understand the reason why they adopted this habit in the first place.

"Information alone is not enough. Some of my colleagues drink too much, and when they hear such information, they make fun of it and don't take it seriously. Maybe they should be frightened off somehow, to understand that this is not a joke." (D.J., 18, boy)

"I think someone should take action regarding these groups. I do not know how, maybe through counseling, disciplining, talking to the family and parents.... Some get to drink a lot and then do other things. They become violent, they threaten you if you try to tell them to stop, they show off and do all kinds of dangerous things..."(M.N., 18 years, girl)

Results show that the interviewed teenagers, although they are generally familiar with the heavy drinking issue, they trifle with it, mostly ignoring the serious and long-term effects of excessive alcohol consumption.

\section{Strategies to prevent alcohol use among adolescents}

The norms and values related to alcohol and behavior towards drinking are not just a personal choice. To a large extent, these are the result of environmental influences, such as "the legislation regarding alcohol use, type of education given by the parents, the rules and behavior of friends or the number of proximal locations where alcoholic drinks can be purchased" (Reijlink, Dalen, \& Petcu, 2011: 16). Because alcohol consumption is linked to many influences from the living environment, prevention actions must be approached not only at the individual level, but also through a change of attitude towards alcohol and towards the drinking patterns. Prevention strategies are based on certain social policies, and the following aspects are generally pursued: " 1 . Raising the level of knowledge and awareness about the health risks of alcohol consumption among adolescents in society in general, or in specific groups; 2 . Increasing the level of knowledge regarding the necessity of adopting policy measures. 3 . Informing the public about policy results, for example through the media" (Reijlink, Dalen, \& Petcu, 2011: 17).

Prevention activities are carried out at the group or individual level by specialists in the socio-human and medical field, within schools, specialized institutions or within associations and NGOs. The National Anti-drug Agency (ANA, 2013) ensures coordination of the activity carried out by the institutions, the governmental organizations, the involvement in achieving the objectives set out in the National 
Anti-Drug Strategy. The territorial structure of ANA comprises 47 Centers for Drug Prevention, Evaluation and Counseling (CPECA). Among prevention activities, information campaigns among students are the most common, exposing the effects of the substances on physical and emotional development of teenagers, on their school performance and health state. Over the recent years, information has been associated with various images, presentations and social cases, with the purpose of raising the awareness in adolescents regarding alcohol use. "However, raising awareness is not sufficient to generate a positive change in behavior, and programs aimed at emotional and interpersonal development do not provide immediate results." (Abraham et. al., 2007: 14)

In addition to information, prevention activities also focused on the families of adolescents with a predisposition towards alcohol consumption. Parents have a key role, and it is necessary that they discuss with their children, especially if there is a history of alcohol consumption in the family, because it is known that alcoholism has a genetic component. Prohibitions are not enough; very clear explanations must be given to teenagers about the risks they face when they drink alcohol, even in small amounts. "Parents have an important influence on alcohol consumption by their children. In order to reduce the harmful effects of alcohol use among young people, parents must receive information on how to cope with alcohol use by adolescents" (Reijlink, Dalen, \& Petcu, 2011: 28)

The National Anti-drug Strategy 2013-2020 (ANA, 2023:21) aims to carry out prevention activities on several levels:

- Prevention in school: increasing the level of information, education and awareness of the student population in order not to start or delay the onset of drug use, implemented in the school curriculum, extra-curricular activities and leisure programs; increasing the level of information, raising awareness among pupils and students in order to avoid transforming experimental and occasional drinking into regular drinking, included in the school curriculum, extra-curricular activities and leisure time programs.

- Prevention in the family: raising awareness and accountability of families in order to provide positive models for children, within the information, education and awareness-raising programs regarding the effects of drug use; developing a proactive role of families in the lives of their children with the purpose of training or strengthening skills for increasing the influence of protective factors.

- Prevention in the community: reducing the influence of risk factors and developing the influence of protection factors within vulnerable groups, correlated with their needs and particularities; reduction in the influence of risk factors and development of the influence of protective factors in professional categories predisposed to drug use, correlated with the level of social responsibility and their particularities; adoption of a healthy lifestyle for the general population, as an alternative to drug use, within leisure programs. 


\section{Conclusion}

A number of adolescents are tempted to drink alcohol for various reasons and influenced by a number of individual, family-related and psychological factors, a.s.o. In the analyzed interview we found that adolescents, although they are familiar with the alcohol drinking issue, they trifle with it and mostly ignore the serious and long-term effects of excessive alcohol consumption. This strengthens the fact that certain psycho-emotional and behavioral imbalances may cause the adolescent to resort to drinking.

In order to prevent alcohol use among adolescents, the specialists recommend, in addition to the aforementioned activities of information, counseling, media messaging, etc., to follow the adoption of certain behavior patterns and to achieve a certain discipline in the life of the adolescent, such as: maintaining a good relationship between the adolescent and the family: effective communication between parents and adolescents, family activities in which the adolescent is involved, parents should be familiar with the group of friends to which the adolescent is affiliated, family responsibilities should be established, the teenager should feel appreciated by family members; fairness and consistency: certain rules should be established that the adolescent should know and respect, the adolescent should have a program and certain responsibilities; Encouraging activities: the adolescent should be encouraged to perform various activities to fill his free time, such as sport or volunteer activities or participation in various clubs.

In this context, it is necessary to provide at least three key ingredients: "an educational environment oriented towards the transmission of values, attitudes and behaviors favorable to health; a set of integrated interventions, based on scientific evidence; educators who should facilitate the formation and use of the personal resources of the students to obtain progressive-evolutionary results" (Abraham, et. al., 2007: 5).

\section{References}

Abraham, P., Georgescu, D., Moldovan, A.M., \& Cicu, G. (2007). Ghid de prevenire a consumului de droguri in randul adolescentilor si tinerilor, Agentia Nationala Antidrog, Bucuresti.

ANA (2013). Strategia Nationala Antidrog 2013-2020, Bucuresti.

Debesse, M. (1970). Psihologia copilului de la nastere la adolescenta, Bucuresti: Editura Didactica si Pedagogica.

Doron, R, \& Parot, F. (2006). Dictionar de Psihologie, Bucuresti : Humanitas.

Dumulescu D., \& Matei, C. (2017). Adolescenta explicata, Buzau: Alpha MDN.

Neamtu, G., \& Stan, D. (2005). Asistenta sociala. Studii si aplicatii, Iasi: Polirom.

Radulescu, S., \& Damboveanu, C. (2006). Consumul si abuzul de alcool ca problema sociala si medicala, Revista Romana de Sociologie, XVII(5-6), 440-453.

Reijlink, L., Dalen, W., Petcu, C. (2011). Manual pentru prevenirea consumului de alcool in Romania, www.drain-project.eu

Zamfir, C., \& Vlasceanu, L. (1998). Dictionar de Sociologie, Bucuresti: Babel. 